\title{
Impacto de los conflictos socioambientales en la gestión turística. Caso departamento de Cajamarca
}

\author{
Impact of socio-environmental conflicts on tourism management. Cajamarca \\ department case
}

Erick Chávez Flores ${ }^{1}$

Recibido: Enero 2020 - Aprobado: Junio 2020 - Publicado: Junio 2020

\begin{abstract}
RESUMEN
La presente investigación tiene como objetivo determinar qué tipos de conflictos socioambientales impactan en la gestión turística, según el promedio de permanencia (días) en el departamento de Cajamarca. Para ello, se desarrolló una investigación con enfoque cuantitativo, el diseño de investigación fue no experimental, de tipo longitudinal y correlacional. Se utilizaron los reportes mensuales de los conflictos sociales de la Defensoría del Pueblo, así también los reportes mensuales estadísticos desde el Ministerio de Comercio Exterior y Turismo (MINCETUR, s. f.) durante el periodo de los años 2005 hasta el 2018. Se aplicó el análisis de correlación y de regresión mediante el programa SPSS 24 (Castañeda et al., 2010). LoS resultados mostraron que, el factor que tiene mayor influencia en el modelo de regresión lineal múltiple son los conflictos socioambientales activos, presentando un impacto negativo en el promedio de permanencia (días) de la población en el departamento de Cajamarca. Además, los conflictos socioambientales activos y latentes tienen una relación de magnitud moderada y tendencia negativa respecto al promedio de visitantes extranjeros a los sitios turísticos, museos y áreas naturales y a la oferta hotelera, según el número de establecimientos de hospedajes respectivamente; mientras los conflictos socioambientales activos con diálogos tienen una relación de magnitud modera y tendencia positiva respecto al arribo de visitantes nacionales y extranjeros al departamento de Cajamarca.
\end{abstract}

Palabras claves: Conflictos socioambientales; gestión turística; regresión lineal múltiple; oferta hotelera; visitantes nacionales.

\begin{abstract}
This research aims to determine what types of socio-environmental conflicts impact tourism management, according to the average stay (days) in the department of Cajamarca. For this, a research with a quantitative approach was developed, the research design was non-experimental, longitudinal and correlational. The monthly reports of the social conflicts of the Ombudsman's Office were used, as well as the monthly statistical reports from the Ministry of Foreign Trade and Tourism (MINCETUR, s. f.) during the period of the years 2005 to 2018. The analysis of correlation and regression using the SPSS 24 program. The results showed that active socio-environmental conflicts are the factor that has the greatest influence on the multiple linear regression model, presenting a negative impact on the average permanence (days) of the population in the department of Cajamarca. In addition, active and latent socio-environmental conflicts have a moderate magnitude relationship and negative trend with respect to the average of foreign visitors to tourist sites, museums and natural areas and to the hotel offer, according to the number of lodging establishments respectively; while active socio-environmental conflicts with dialogues have a moderate magnitude relationship and a positive trend regarding the arrival of national and foreign visitors to the department of Cajamarca.
\end{abstract}

Keywords: Socio-environmental conflicts; tourism management; multiple linear regression; hotel offer; national visitors.

\footnotetext{
${ }^{1}$ Egresado de la Unidad de Posgrado, Facultad de Ingeniería Geológica, Minera, Metalúrgica y Geográfica, Universidad Nacional Mayor de San Marcos. Lima, Perú. E-mail: erick.chavez@unmsm.edu.pe, msc.chavezf@gmail.com
} 


\section{INTRODUCCIÓN}

En la actualidad, la economía de nuestro país sigue generando un crecimiento moderado - pese a la crisis internacional del año 2008 - impulsado básicamente por la inversión privada y por la expansión de los sectores de la construcción, comercio y la minería. Sin embargo, el sector minero sigue siendo un factor importante para la economía del país, ya que genera divisas y es fuente de empleo directo e indirecto. Así mismo el sector comercio y la actividad turística son las principales herramientas para la generación de empleo y lo convierte en un gran potencial para el desarrollo económico de la región. Cajamarca es uno de los principales mercados de destino turístico en el Perú. Sin embargo, la falta de gestión y políticas públicas adecuadas reducen los beneficios que conduce dicha actividad, lo cual genera disconformidad en las poblaciones de las comunidades, y esto se ve reflejado en la baja calidad de vida de estas provincias. En esta perspectiva, los conflictos socioambientales se han convertido en un grave problema para el Estado y las comunidades, debido a que generan un malestar perjudicando la imagen de un país que se considera económicamente estable e indicadores socioeconómicos favorables, existiendo otros factores subyacentes que sea atractivo para los inversionistas y su decisión en invertir en proyectos macroregionales.

\subsection{Turismo}

En la actualidad, existe una amplitud de conceptos acerca del turismo que han dado diversos autores, que permiten describir su evolución a través del tiempo. La definición universalmente utilizada es de la Organización Mundial de Turismo (OMT) que la define como: "Las actividades que realizan las personas durante sus viajes y estancias en lugares distintos al de su entorno habitual, por un periodo consecutivo inferior a un año con fines de ocio, por negocios y otros" (p.143) citado en (Morillo Moreno, 2011). La actividad turística permite desarrollar nuevos destinos turísticos y revalorizar el patrimonio cultural, teniendo un impacto en la calidad de vida de las personas donde se concentra el turismo.

El turismo se puede clasificar de diferentes formas, de acuerdo a la actividad que realiza el turista; (Sáez et al., 2006) describe una clasificación según el destino del viaje como: (1) turismo emisor, realizado por los visitantes residentes en su propio país. (2) turismo receptor, realizado por los visitantes extranjeros en un país de referencia y (3) turismo emisor, realizado por los residentes fuera de sus fronteras. Asimismo, (Oliva, M. y Lonardi, P., 2017) señalan otras tres formas de turismo según el gasto turístico: (1) Turismo interior, comprende el turismo interno y el turismo receptor, (2) turismo nacional, comprende el turismo interno y el turismo emisor, y (3) turismo internacional, comprende turismo receptor y el turismo emisor.

Si bien el desarrollo turístico impulsa la estrategia de fomento económico mediante la actividad turística, también se asumen ciertos impactos tanto positivos como negativos. («Tinoco, O.», 2003) señala que la actividad turística genera un efecto multiplicador en la generación de empleo, expansión del sector privado y su impacto económico equilibrando la balanza de pago y la distribución de la renta. Ciertamente, el efecto inmediato que genera el turismo es el consumo que realizan los turistas y/o residentes que impulsan el desarrollo económico nacional o regional y se interrelaciona con la generación de empleo a través de las actividades extractivas, comercio, manufactura, etc. Aunque también presenta impactos negativos tanto en lo económico, social y cultural como: modificación de la estructura económica de las regiones, contaminación ambiental, alteración del habitad natural y transculturación. Es importante que un país emergente con escaso empleo, potencie sus recursos naturales y patrimoniales pero previniendo de algún daño a futuro y logre un adecuado desarrollo que contribuya a su región.

De acuerdo con (Peña, L., 2014), la gestión turística busca lograr resultados óptimos de los recursos turísticos fomentando un desarrollo sustentable con la finalidad de captar y fidelizar a los turistas. Cabe resaltar la importancia del destino turístico, que debe articular de manera armónica con las políticas públicas y los inversionistas como parte de un sistema en su conjunto. También se destaca los principales objetivos de la gestión turística como: fomentar la diversidad cultural, folclórica, natural y étnica de manera responsable en conjunto con el recurso turístico acorde con la participación de la sociedad y los organismos responsables.

\subsection{Conflicto Socioambiental}

La (Defensoria del Pueblo, 2018) en su reporte mensual $\mathrm{N}^{\circ} 173$ de conflictos sociales describe dentro de la tipología de conflictos sociales, de tipo socioambiental y lo define como: "control, uso y/o acceso al ambiente y sus recursos. Están presentes también componentes políticos, económicos, sociales y culturales" (p.4). El conflicto que tiene mayor predominio está relacionado con la minería e hidrocarburos. Desde el año 2005 la Defensoría del Pueblo es la institución encargada de realizar los monitoreos de los conflictos sociales. Asimismo, según el estado de los conflictos estos pueden ser:

- Conflicto activo, se manifiesta cunado algunos de los actores o por terceros expresan sus demandas públicas.

- Conflicto latente, es cuando el conflicto permanece inactivo o silenciosos, que no se manifiesta públicamente.

- Conflicto activo con dialogo, es cuando se desarrolla una comunicación en los actores intercambian sus opiniones con la finalidad de establecer acuerdos.

Los conflictos socioambientales activos si bien siguen un proceso, pueden estar afectos a otros factores externos que pueden distorsionar esa tendencia de evolución que pueden interrumpir la fase del diálogo o negociación entre los actores primarios, secundarios y terciarios.

Los impactos de los conflictos socioambientales referidos a la minería en la última década según (Saade, 2013) se dan en dos aspectos: (a) Costos económicos y financieros: La masificación de proyectos mineros en el caso de Perú han contribuido a un incremento de la inversión privada. Sin embargo, también se han desarrollado múltiples conflictos sociales, de tipo socioambiental, que 
se encontraban en estados latentes. Aunque el desarrollo donde se concentra los proyectos mineros trae beneficios para unos cuantos pobladores también tiene impactos negativos, como incremento de precios, prostitución, inequidad de salarios generando cierto rechazo por parte de la población y (b) Costos sociales y ambientales: Son los referidos a la afectación de la salud como los pasivos ambientales mineros que no tendrían un cierre de mina adecuado y tendrían un impacto de riesgo a la salud.

\section{METODOLOGÍA}

La presenta investigación tiene un enfoque cuantitativo ya que se pretende medir el impacto de los conflictos socioambientales para probar las hipótesis de investigación mediante los análisis estadísticos (Hernández Sampieri et al., 2007). El diseño de la investigación es no experimental, ya que las variables no se manipularan; de tipo longitudinal, y correlacional para contrastar si las variables de estudio se encuentran relacionadas. Para la recopilación de información, se empleó el análisis documental mediante los reportes de los conflictos sociales mensuales de la Defensoría del Pueblo y los reportes estadísticos mensuales del MINCETUR desde el año 2005 hasta el 2018. Mediante el programa estadístico SPSS 24 se aplicaron el análisis de correlación y de regresión para la validación de las hipótesis de investigación.

\section{RESULTADOS}

En la Tabla 1, se observa los indicadores del modelo de regresión lineal múltiple por medio del método por pasos sucesivos, el cual arrojó como resultado un coeficiente de determinación $\left(\mathrm{R}^{2}\right)$ esto significa que el $80.0 \%$ de la variación del promedio de permanencia es explicado por los conflictos socioambientales activos. Asimismo, el valor de coeficiente de determinación ajustado $\left(\mathrm{R}^{2}\right.$ corregido) indica que el $78.4 \%$ de la variación del promedio de permanencia es explicado por los conflictos socioambientales activos.

Tabla 1. Indicadores del modelo de regresión

\begin{tabular}{cccc}
\hline Modelo & $\mathbf{R}$ & $\mathbf{R}^{2}$ & $\begin{array}{c}\mathbf{R} 2 \text { cuadrado } \\
\text { ajustado }\end{array}$ \\
\hline 1 & $0.895^{\mathrm{a}}$ & 0.80 & 0.784 \\
\hline
\end{tabular}

a. Predictores: (Constante), conflictos socioambientales activos,

*Método: pasos sucesivos

En la Tabla 2, la Tabla ANOVA, el estadístico F tiene un valor de 48.084 y su valor de significancia (Sig.) asociado es de 0.000 menor al nivel de significancia $(\alpha$ $=0.05$ ); al rechazar la hipótesis nula al menos una de las variables independientes tendrá una relación significativa y contribuirán en la predicción del modelo («Véliz, C.», 2011). Por lo tanto, el modelo de regresión propuesto cumple con el rechazo de la hipótesis nula, es decir, el modelo es adecuado para realizar la predicción.

En la Tabla 3, cuadro de coeficientes, la constante del modelo y la variable conflictos socioambientales activos (CSAC) tienen un valor de significancia (Sig.) asociado de 0.000 respectivamente, al ser valores menores al nivel de significancia $(\alpha=0.05)$ son significativos para el modelo de regresión. Por lo tanto, los conflictos socioambientales activos influyen en la predicción del modelo.

Tabla 2. Tabla ANOVAa

\begin{tabular}{lccccc}
\hline Modelo & $\begin{array}{c}\text { Suma de } \\
\text { cuadrados }\end{array}$ & gl & $\begin{array}{c}\text { Media } \\
\text { cuadrática }\end{array}$ & F & Sig. \\
\hline Regresión & 0.099 & 1 & 0.099 & 48.084 & $0,000^{\mathrm{b}}$ \\
1 Residuo & 0.025 & 12 & 0.002 & & \\
$\quad$ Total & 0.124 & 13 & & \\
\hline a. Variable dependiente: Promedio de permanencia turística & \\
b. Predictores: (Constante), conflictos socioambientales activos &
\end{tabular}

Tabla 3. Cuadro de coeficientes ${ }^{a}$

\begin{tabular}{|c|c|c|c|c|c|c|}
\hline & \multirow{2}{*}{ Modelo } & \multicolumn{2}{|c|}{$\begin{array}{l}\text { Coeficientes no } \\
\text { estandarizados }\end{array}$} & \multirow{2}{*}{$\begin{array}{c}\begin{array}{c}\text { Coeficientes } \\
\text { estandarizados }\end{array} \\
\text { Beta }\end{array}$} & \multirow{2}{*}{$t$} & \multirow{2}{*}{ Sig. } \\
\hline & & B & $\begin{array}{l}\text { Error } \\
\text { estándar }\end{array}$ & & & \\
\hline & (Constante) & 1.557 & 0.028 & & 54.783 & 0.000 \\
\hline 1 & $\begin{array}{l}\text { Conflictos } \\
\text { Socioambientales } \\
\text { Activos (CSAC) }\end{array}$ & -0.002 & 0 & -0.895 & -6.934 & 0.000 \\
\hline
\end{tabular}

a. Variable dependiente: promedio de permanencia

El modelo estimado es:

$$
\stackrel{\tilde{y}}{\tilde{y}}=1.557-0.002 * C S A C
$$

La variable CSAC (conflictos socioambientales activos) es significativo para el modelo de regresión e influye negativamente en la gestión turística según el promedio de permanencia (días) respecto de los otros factores como los conflictos socioambientales latentes y los conflictos socioambientales activos con diálogos.

En la Tabla 4, muestra la correlación entre los conflictos socioambientales activos y el promedio de visitantes extranjeros a sitios turísticos, museos y áreas naturales al departamento de Cajamarca presentan una probabilidad de significancia $(\rho=0.009)$ menor al nivel de significancia $(\alpha=0.05)$. Por lo tanto, existe una relación moderada y negativa $(r=-0.623)$ entre ambas variables.

Tabla 4. Correlación entre los conflictos socioambientales activos y el promedio de visitantes extranjeros a sitios turísticos, museos y áreas naturales

\begin{tabular}{lccc}
\hline \multirow{2}{*}{$\begin{array}{l}\text { Promedio de visitantes extranjeros a sitios turísticos, } \\
\text { museos y áreas naturales al departamento de Cajamarca }\end{array}$} \\
\cline { 2 - 4 } & $\mathbf{r}$ & $\mathbf{p}$ & $\mathbf{n}$ \\
\hline Conflictos socioambientales activos & -0.623 & 0.009 & 14 \\
\hline
\end{tabular}

Nota: $r=$ coeficiente de correlación de Pearson significativo en el nivel 0,05 (unilateral), $\mathrm{p}=$ probabilidad de significancia y $\mathrm{n}=$ número de casos

En la Tabla 5, muestra la correlación entre los conflictos socioambientales latentes y la oferta hotelera según el número de establecimientos de hospedajes en el departamento de Cajamarca presentan una probabilidad de significancia $(\rho=0.000)$ menor al nivel de significancia $(\alpha=0.05)$. Por lo tanto, existe una relación moderada y negativa $(r=-0.798)$ entre ambas variables. 
Tabla 5. Correlación entre los conflictos socioambientales latentes y oferta hotelera según el número de establecimientos de hospedajes

\begin{tabular}{lccc}
\hline \multicolumn{2}{l}{ Oferta hotelera (número de establecimientos de hospedajes) } \\
\cline { 2 - 4 } & $\mathbf{r}$ & $\mathbf{p}$ & $\mathbf{n}$ \\
\hline Conflictos socioambientales latentes & -0.798 & 0.000 & 14 \\
\hline
\end{tabular}

Nota: $r$ = coeficiente de correlación de Pearson significativo en el nivel 0,01 (unilateral), $p=$ probabilidad de significancia y $n=$ número de casos

En la Tabla 6, muestra la correlación entre los conflictos socioambientales activos con dialogo y el arribo de visitantes nacionales y extranjeros al departamento de Cajamarca presentan una probabilidad de significancia $(\rho$ $=0.000)$ menor al nivel de significancia $(\alpha=0.05)$. Por lo tanto, existe una relación baja y positiva $(\mathrm{r}=0.464)$ entre ambas variables.

Tabla 6. Correlación entre conflictos socioambientales activos con dialogo y el arribo de visitantes nacionales y extranjeros

\begin{tabular}{llccc}
\hline \multirow{2}{*}{$\begin{array}{l}\text { Arribo de visitantes nacionales y extranjeros al departamento } \\
\text { de Cajamarca }\end{array}$} & & \multicolumn{3}{l}{} \\
\cline { 2 - 5 } & $\mathbf{r}$ & $\mathbf{p}$ & $\mathbf{n}$ \\
\hline $\begin{array}{l}\text { Conflictos socioambientales } \\
\text { dialogo }\end{array}$ & activos con & $0.464^{*}$ & 0.047 & 14 \\
\hline
\end{tabular}

Nota: $r$ = coeficiente de correlación de Pearson significativo en el nivel 0,05 (unilateral), $p=$ probabilidad de significancia y $n=$ número de casos

\section{DISCUSIÓN}

La investigación evidencia que los conflictos socioambientales activos influyen de forma negativa en la gestión turística según el promedio de permanencia turística, provocando impacto negativo en el desarrollo económico en el departamento de Cajamarca. De acuerdo con (Kuhn, 2011), esto se genera por la escaza presencia del Estado y la ausencia de políticas adecuadas para regular los proyectos mineros. Provocando de esta manera el conflicto entre la inversión privada y las comunidades, ante la falta de reacción del Estado por solucionar de manera eficiente y teniendo un impacto en el ámbito político, social y económico. Es vital que exista el dialogo antes o durante el inicio de los conflicto socioambientales con la finalidad de generar confianza entre la población y permitan un dialogo con el Estado. Se debe promover la conservación y protección de los recursos turísticos ya que es crucial en la actividad turística teniendo un equilibro entre los intereses particulares y el bienestar para una población (Vasquez, M., 2011). De esta manera se mantendrá un normal desarrollo de las actividades económicas, turísticas y culturales.

\section{CONCLUSIONES}

1. De acuerdo al promedio de permanencia (días) se obtuvo que, la gestión turística tiene el factor de influencia en el modelo. Respecto a los conflictos socioambientales activos, conflictos socioambientales latentes y conflictos socioambientales activos con diálogos mediante el análisis de regresión lineal múltiple por el método de pasos sucesivos, son los conflictos socioambientales activos que presentan un impacto negativo. Es decir que, ante un aumento del número de conflictos socioambientales activos se genera una disminución en el promedio de permanencia (días) de la población nacional como extranjera en el departamento de Cajamarca.

2. Existe una relación significativa entre los conflictos socioambientales activos y el promedio de visitantes extranjeros a los sitios turísticos, museos y áreas naturales al departamento de Cajamarca, siendo esta relación $(\mathrm{r}=-0.623)$ de magnitud moderada y tendencia negativa.

3. Existe una relación significativa entre los conflictos socioambientales latentes y la oferta hotelera según el número de establecimientos de hospedajes; siendo esta relación $(r=-0.798)$ de magnitud moderada $y$ tendencia negativa.

4. Existe una relación significativa entre los conflictos socioambientales activos con dialogo y arribo de visitantes nacionales y extranjeros al departamento de Cajamarca; siendo esta relación $(r=0.464)$ de magnitud baja y tendencia positiva.

\section{AGRADECIMIENTOS}

A la Revista del Instituto de Investigaciones de la Facultad de Geología, Minas, Metalurgia y Ciencias Geográfica de la Universidad Nacional Mayor de San Marcos por permitir la publicación de la presente investigación.

\section{REFERENCIAS}

Castañeda, M. B., Cabrera, A. F., \& Navarro, Y. (2010). Procesamiento de datos y análisis estadísticos utilizando SPSS: Un libro práctico para investigadores y administradores educativos. http://www.pucrs.br/edipucrs/ spss.pdf

Defensoria del Pueblo. (2018). Defensoria del Pueblo - Perú. https://www.defensoria.gob.pe/documentos/reportemensual-n-173-julio-2018/

Hernández Sampieri, R., Fernández Collado, C., \& Baptista Lucio, P. (2007). Metodología de la investigación (4ta.). McGraw-Hill. https://investigar1.files.wordpress. com/2010/05/1033525612-mtis_sampieri_unidad_1-1.pdf

Kuhn, R. (2011). No todo lo que brilla es oro: Conflictos socio ambientales alrededor de dos proyectos de minería a gran escala en el Ecuador. http://repositorio.uasb.edu.ec/ handle/10644/2259

MINCETUR. (s. f.). Estadística Mensual de Turismo para Establecimientos de Hospedaje. Recuperado 9 de junio de 2020, de http://consultasenlinea.mincetur.gob.pe/ encuestaMensual/

Morillo Moreno, M. C. M. (2011). Turismo y producto turístico. Evolución, conceptos, componentes y clasificación. Visión Gerencial; Universidad de los Andes. https://www.redalyc. org/articulo.oa?id=465545890011 
Oliva, M. y Lonardi, P. (2017, noviembre 5). casadellibro. https://www.casadellibro.com/ebook-metodologiade-la-investigacion-social-aplicada-al-turismoebook/9789879468579/6017170

Peña, L. (2014). La Planificación y Gestión Pública En El Turismo. Su Impacto En La Ejecución de Proyectos. Pro Desarrollo Turístico. https://issuu.com/prodesarrolloturisticoperu/docs/ pip

Saade, M. (2013). Desarrollo minero y conflictos socioambientales. Comisión Económica para América Latina y el CaribeCEPAL. Desarrollo minero y conflictos socioambientales Los casos de Colombia, México y el Perú, $N^{\circ}$ 137, 58.

Sáez, A., Urbano, P. M., \& Fernández, J. I. P. (2006). Estructura económica del turismo. Síntesis. https://dialnet.unirioja.es/ servlet/libro? codigo $=10377$
Tinoco, O. (2003). Los impactos del turismo en el Perú. Industrial Data., 6(1), 047-060. https://doi.org/10.15381/idata. v6i1.5982

Vasquez, M. (2011). Análisis de conflictos socioambientales en el parque natural de Las Lagunas de Ruidera: La influencia de la agricultura de regadío sobre el turismo. Revista Investigaciones Turísticas, 2. https://doi.org/10.14198/ INTURI2011.2.06

Véliz, C. (2011). Estadistica Para La Administración y Los Negocios. https://www.academia.edu/39346794/ Estad\%C3\%ADstica para la administraci\%C3\%B3n y los_negocios_-_Carlos_V\% $\mathrm{C} 3 \% \mathrm{~A} 91 \mathrm{liz} \_\mathrm{Capu} \% \mathrm{C} 3 \% \mathrm{~B} 1 \mathrm{ay}$ _$1 \overline{E D}$ 
